\title{
Adsorptive Removal of Chromium (VI) by Papaya Seed from Aqueous Media
}

\author{
Deji K.C. and Khagendra Prasad Bohara* \\ Central Department of Chemistry, Tribhuvan University, Kirtipur, Kathmandu, Nepal \\ E-mail:- khagendra_arsenic@yahoo.com
}

\begin{abstract}
Batch adsorptive removal of chromium (VI) from aqueous solution using raw papaya seed powder (RPS) was investigated as a function of $\mathrm{pH}$, equilibrium time, amount of adsorbent and concentration of chromium(VI). Adsorption efficiency is highly $\mathrm{pH}$ dependent and the results indicate that the optimum removal was achieved at $\mathrm{pH} 1$. Kinetics and isotherm modeling studies demonstrated that the experimental data best fitted a pseudo-second order and Langmuir isotherm model, respectively. The maximum Langmuir adsorption capacity was found to $106.25 \mathrm{mg} / \mathrm{g}$.
\end{abstract}

Key Words: Chromium(VI), Adsorption, Papaya Seed, Isotherm, Kinetic

\section{Introduction}

Chromium is a common and very toxic pollutant introduced into natural waters from a variety of industrial wastewaters. The main industrial sources of chromium in water are leather tanning, electroplating, dyeing, steel fabrication, agricultural runoff. Chromium is also used in explosive, ceramics and photography ${ }^{1,2}$.

Chromium exists in environment both as trivalent and hexavalent forms of which hexavalent form of chromium is 500 times more toxic than trivalent one. Human toxicity of $\mathrm{Cr}(\mathrm{VI})$ includes skin irritation, lung cancer, as well as kidney, liver and gastrum damage ${ }^{2}$. Hexavalent chromium which is primarily present in the form of chromate $\left(\mathrm{CrO}_{4}{ }^{2-}\right)$ and dichromate $\left(\mathrm{Cr}_{2} \mathrm{O}_{7}{ }^{2-}\right)$ possesses significantly higher level of toxicity than other valency states $^{3}$. $\mathrm{Cr}(\mathrm{VI})$ ions mostly exists in anionic form at highly acidic medium $(\mathrm{pH}=1)$. At $\mathrm{pH} 2-6$ there is equilibrium between the anionic species ${ }^{4}$. Hexavalent chromium has been reported to be carcinogenic. The tolerance limit for $\mathrm{Cr}(\mathrm{VI})$ for discharge into inland surface water is $0.1 \mathrm{mg} / \mathrm{l}$ and potable water is $0.05 \mathrm{mg} / \mathrm{l}^{5}$. To comply with the limit, industrial effluents need to be treated to reduce the $\mathrm{Cr}(\mathrm{VI})$ to acceptable level.

A number of treatment methods have been reported for removal of metal ions from aqueous solutions. The most commonly employed process of treating waste water containing $\mathrm{Cr}(\mathrm{VI})$ include its reduction to trivalent state by addition of reducing agents (e.g. $\mathrm{NaHSO}_{3}$ and $\mathrm{FeSO}_{4}$ ) followed by alkaline precipitation of $\mathrm{Cr}(\mathrm{OH})_{3}{ }^{6}$. This method is reliable but requires large settling tanks for precipitation of voluminous hydroxides and subsequent sludge treatment and its disposal. Other methods are ion exchange,

\footnotetext{
* Corresponding author
} 


\section{J. Nepal Chem. Soc., Vol. 39, 2018}

electrodialysis, electrochemical precipitation, evaporation, solvent extraction, reverse osmosis and adsorption on activated carbon. ${ }^{7}$ But most of these methods suffer from drawbacks due to high capital investment, high operational and maintenance cost and safe disposal of the residual metal sludge. These methods are limited by technical and economical constrains, especially when concentration is below 100 $\mathrm{mg} / \mathrm{L}$. In such cases adsorption is promising technique ${ }^{8}$. Adsorption has advantages over the other methods because it is simple in design and requires low operational cost ${ }^{9}$.

Recently, agro wastes containing functional groups associated with proteins, polysaccharides and cellulose as major constituents have been used as adsorbents for the removal of metal ions from aqueous solutions since it offers flexibility in design and operation with the advantages such as: low cost, high efficiency, minimization of sludge, regeneration ability and possibility of metal recovery. ${ }^{10,11}$ The metal ion binding occurs as a result of physiochemical interactions, mainly ion exchange or surface complex formation between metal ions and the acidic functional groups present on the surface of adsorbent. ${ }^{12}$

The effectiveness of different biological materials such as cactus and pine needles ${ }^{2}$, sphagnum moss peat $^{3}$, maize bran ${ }^{13}$, saw dust ${ }^{14}$, rice husk ${ }^{15}$, activated cow dung carbon ${ }^{16}$, filamentous algae ${ }^{17}$, tamarind hull ${ }^{18}$, grape waste ${ }^{19}$, moss $^{20}$, corn $\operatorname{cob}^{21}$, coconut husk and palm pressed fibres ${ }^{22}$, sunflower waste ${ }^{23}$, green Moringa tea leaves ${ }^{24}$, wheat straw and Eupatorium adenophorum stem $^{25}$, rice straw $^{26}$ towards the adsorption of chromium(VI) from aqueous media have been reported by a number of researchers.

Papaya seed is one of the commonly discarded agro-waste. Papaya seed is composed of lignin and cellulose as major constituents and contain other polar functional groups of lignin, which include alcohols, aldehydes, ketones, carboxylic, phenolic, and ether groups. These groups have ability to bind heavy metal ions by donation of an electron pair from these groups to form complexes with the metal ions in solution. ${ }^{27}$ The use of papaya seeds as adsorbent is very interesting from environmental and economic point of view since it is an agricultural residue that is available at low cost.

In this study, papaya seed from agricultural waste is explored for the adsorptive removal of $\mathrm{Cr}(\mathrm{VI})$ from aqueous solution at room temperature.

\section{Experimental Methods}

\section{Metal ion solution preparation}

Chromium(VI) stock solution was prepared by dissolving predefined amount of an analytical grade, potassium dichromate in distilled water in volumetric flask, so as to achieve concentration of $1000 \mathrm{mg} / \mathrm{L}$. Laboratory distilled water was used for the preparation of standard chromium(VI) samples from the stock solution.

\section{Preparation of Adsorbent}

Raw papaya seed collected was washed thoroughly with distilled water to remove dust particles. It was left at room temperature for 1 day to ooze out excess water and was dried in air dry oven at $105{ }^{\circ} \mathrm{C}$ for 24 hours. The dried papaya seed was then grinded in to small particle size and was sieved by 212 micron mesh to obtain definite particle size raw papaya seed powder (RPS). 


\section{Adsorption experiments and analysis}

Experiments were performed in $125 \mathrm{~mL}$ reagent bottle in batch mode taking $25 \mathrm{~mL}, \mathrm{pH}$ adjusted synthetic working solutions of chromium(VI) of predetermined initial concentrations and pre-defined amounts of adsorbent, raw papaya seed powder (RPS), at room temperature. The reagent bottle was shaken in mechanical shaker at speed of $200 \mathrm{rpm}$ to attain equilibrium. The equilibrated solution was filtered using ordinary filter paper and the filtrate was analyzed for the residual concentration of chromium(VI) ions. The metal concentration before and after adsorption were determined by using WPAS-104 Spectrophotometer, at 540nm using 1,5-Diphenyl carbazide solution in acidic medium. ${ }^{28}$ The $\mathrm{pH}$ of each solution was adjusted to the desired value using $0.1 \mathrm{M} \mathrm{HNO}_{3}$ and $0.1 \mathrm{M} \mathrm{NaOH}$ solutions. $\mathrm{pH}$ measurements were carried out using $\mathrm{pH}$ meter. All experiments were performed in triplicate and average values are reported. Concentration of chromium(VI) retained in the adsorbent at equilibrium $\left(\mathrm{q}_{\mathrm{e}} ; \mathrm{mg} / \mathrm{g}\right)$, and the adsorption efficiency (\% removal), were computed according to the expressions (1) and (2).

$$
\begin{aligned}
& \mathrm{q}_{\mathrm{e}}=\frac{\left(\mathrm{C}_{\mathrm{i}}-\mathrm{C}_{\mathrm{e}}\right) \mathrm{V}}{\mathrm{m}} \mathrm{mg} / \mathrm{g} \\
& \% \text { Removal }=\frac{\left(\mathrm{C}_{\mathrm{i}}-\mathrm{C}_{\mathrm{e}}\right) 100}{\left(\mathrm{C}_{\mathrm{i}}\right.}
\end{aligned}
$$

Where $\mathrm{C}_{\mathrm{i}}$ and $\mathrm{C}_{\mathrm{e}}$ are the initial and equilibrium or final concentrations of the chromium(VI) in $\mathrm{mg} / \mathrm{L}$ respectively, $\mathrm{V}$ is volume of the chromium(VI) solution taken in litre (L) and $\mathrm{m}$ is the mass of the adsorbent in $\operatorname{gram}(\mathrm{g})$.

The effect of initial $\mathrm{pH}$, adsorbent dose, contact time, and initial chromium(VI) concentration were investigated by varying any one of the process parameters keeping the others constant.

\section{Results and Discussion}

\section{Effect of $p H$}

To evaluate the influence of $\mathrm{pH}$ on the sorption process, experiments were carried out at different initial $\mathrm{pH}$. The effect of $\mathrm{pH}$ on the sorption efficiencies of chromium(VI) on the raw papaya seed powder is shown in figure 1.

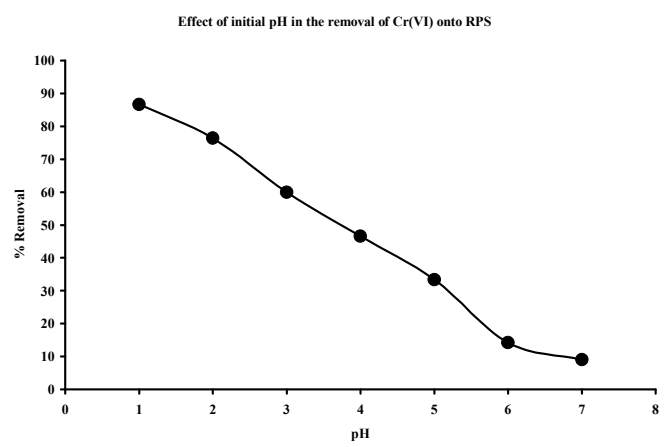

Figure 1: Effect of $p H$ on the adsorption onto RPS. 


\section{J. Nepal Chem. Soc., Vol. 39, 2018}

Removal of chromium(VI) decreased with the increase in $\mathrm{pH}$ and the optimum $\mathrm{pH}$ for the maximum uptake was found to be 1 . The high degree of adsorption at low $\mathrm{pH}$ can be explained by the fact that at low $\mathrm{pH}, \mathrm{Cr}(\mathrm{VI})$ exists in the form of oxyanions such as $\mathrm{HCrO}_{4}^{-}, \mathrm{Cr}_{2} \mathrm{O}_{7}{ }^{2-}, \mathrm{CrO}_{4}{ }^{2-}$, etc and lowering of $\mathrm{pH}$ caused the surface of the adsorbents to be protonated to a greater extent as a result a strong electroststic attraction exists between the oxyanions of $\mathrm{Cr}(\mathrm{VI})$ and the positively charged surface of the adsorbents. As a consequence the uptake increases with decrease in $\mathrm{pH}$ of the solution, whereas at high $\mathrm{pH}$ adsorbent surface will be negatively charged there by causing hindrance in the adsorption of oxyanions of $\mathrm{Cr}(\mathrm{VI})$ resulting in decrease in removal efficiency at high $\mathrm{pH}$, which indicates that sorption of $\mathrm{Cr}(\mathrm{VI})$ in aqueous solution through anion sorption mechanism. Similar findings have been reported by others. ${ }^{14,29}$

\section{Effect of Adsorbent Dose}

The effect of adsorbent dose was studied by varying the amount of adsorbent from $25 \mathrm{mg}$ to $150 \mathrm{mg}$ and equilibrated for 24 hours at $\mathrm{pH} 1$ and at initial $\mathrm{Cr}(\mathrm{VI})$ ion concentration $5 \mathrm{mg} / \mathrm{L}$. The effect of adsorbent dose on the adsorption efficiency of $\mathrm{Cr}(\mathrm{VI})$ by RPS is shown in figure 2 which shows that the adsorption of $\mathrm{Cr}(\mathrm{VI})$ was found to be increased with an increase in adsorbent dose initially but adsorption remains almost unchanged after adsorbent dose of $100 \mathrm{mg}$.

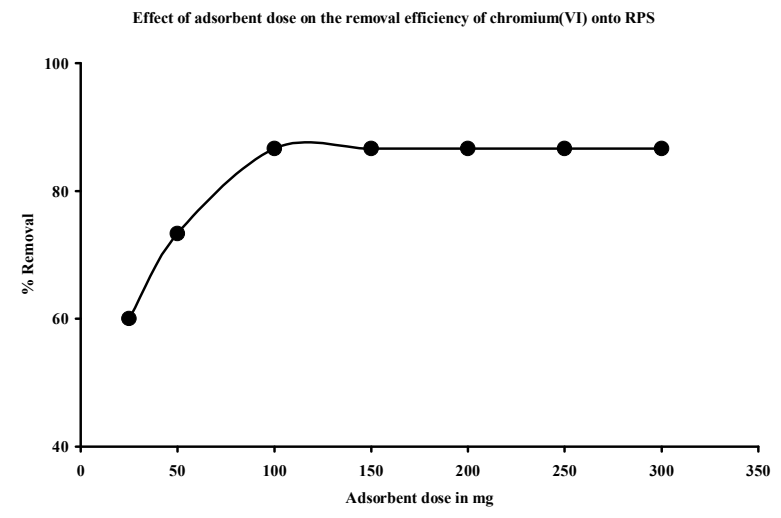

Figure 2: Effect of adsorbent Dose on the adsorption onto RPS.

Increase in adsorption with increase in adsorbent doses attributed to the availability of large surface area and more adsorption sites. At low adsorbent dose, the adsorbent surface becomes saturated with $\mathrm{Cr}(\mathrm{VI})$ and the corresponding residual $\mathrm{Cr}(\mathrm{VI})$ ion concentration in the solutions is large. ${ }^{30}$

\section{Effect of contact time}

The effect of contact time on the adsorption of $\mathrm{Cr}(\mathrm{VI})$ was studied by taking $50 \mathrm{~mL}$ aliquot of $5 \mathrm{mg} / \mathrm{L}$ $\mathrm{Cr}(\mathrm{VI})$ solution with $50 \mathrm{mg}$ of adsorbent, and shaking at a speed of $200 \mathrm{rpm}$ in the range 2 to 120 minutes. 


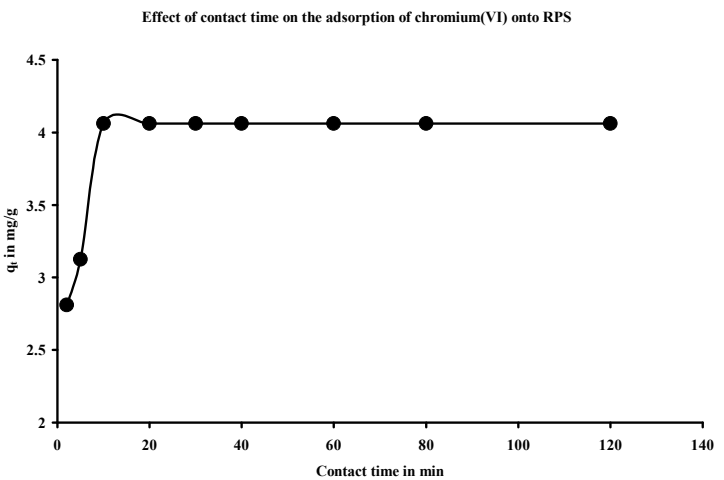

Figure 3: Effect of Contact Time on the adsorption onto RPS.

The equilibrium contact time for adsorption of $\mathrm{Cr}(\mathrm{VI})$ on to RPS reached within the first 10 minutes as shown in figure 3. The experimental results showed that the adsorption rate was rapid at first because of the presence of large number of adsorption sites so that large amount of $\mathrm{Cr}(\mathrm{VI})$ oxyanions attached selectively to the adsorbent sites initially. The chromium(VI) removal gradually reduced till it attained equilibrium at specific time for the adsorbents beyond which there was no significant increase in adsorption rate due to decrease in active adsorption sites in the adsorbent and after reaching the saturation point adsorption becomes constant. Significant adsorption efficiency of RPS could be attributed to the higher availability of different oxyanion selective surface functional groups. ${ }^{27,30}$

\section{Effect of Initial Concentration}

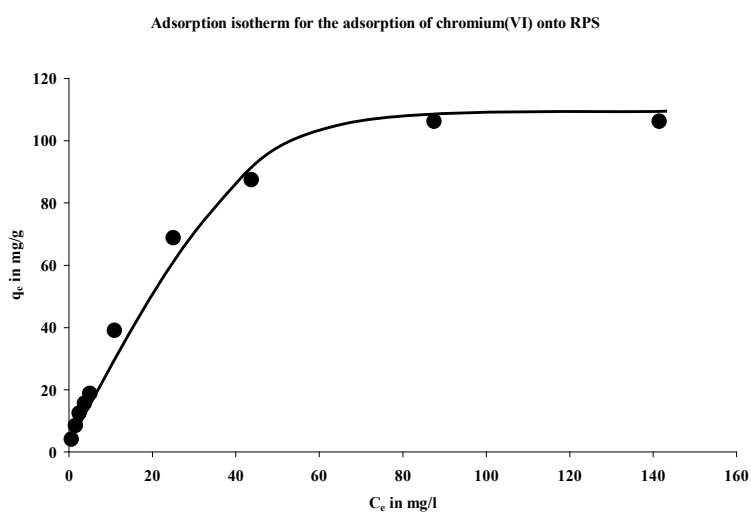

Figure 4: Effect of Initial Concentration on the adsorption onto RPS.

The effect of $\mathrm{Cr}(\mathrm{VI})$ concentration is shown in figure 4 which shows that adsorption of $\mathrm{Cr}(\mathrm{VI})$ on raw papaya seed powder increases with increase in initial concentration of $\mathrm{Cr}(\mathrm{VI})$ solution and attains equilibrium which is attributed to the availability of limited adsorption sites. The increase in concentration of $\mathrm{Cr}(\mathrm{VI})$ increases the mass transfer driving force and therefore increases the rate at which $\mathrm{Cr}(\mathrm{VI})$ ions pass from the bulk solution to the particle surface that would results in higher adsorption. ${ }^{31}$ 


\section{J. Nepal Chem. Soc., Vol. 39, 2018}

It was found that on changing the initial concentration of $\mathrm{Cr}(\mathrm{VI})$ from 5 to $250 \mathrm{mg} / \mathrm{L}$ the amount adsorbed increased from $4.06 \mathrm{mg} / \mathrm{g}$ to $106.25 \mathrm{mg} / \mathrm{g}$ at optimum $\mathrm{pH} 1$ signifying that the RPS is effective for the adsorptive removal of $\mathrm{Cr}(\mathrm{VI})$ from aqueous solution.

\section{Isotherm modeling}

The experimental data for the adsorptive removal of chromium(VI) from aqueous solution was analyzed by using Langmuir and Freundlich isotherm models. The Langmuir isotherm ${ }^{32,33}$ assumes monolayer adsorption onto a surface with a finite number of identical sites with homogeneous adsorption energy, and its linear form can be expressed as follows:

$$
\mathrm{C}_{\mathrm{e}} / \mathrm{q}_{\mathrm{e}}=1 / \mathrm{q}_{\mathrm{m}} \mathrm{b}+\mathrm{C}_{\mathrm{e}} / \mathrm{q}_{\mathrm{m}}
$$

Where, $q_{e}$ is the amount of adsorbate adsorbed per unit mass of adsorbent at equilibrium in (mg/g), $C_{e}$ is the equilibrium concentration of the adsorbate in $\mathrm{mg} / \mathrm{L}, \mathrm{q}_{\mathrm{m}}$ is the maximum adsorption capacity $(\mathrm{mg} / \mathrm{g})$ and ' $\mathrm{b}$ ' is the Langmuir adsorption equilibrium constant $1 / \mathrm{mg}$.

The Freundlich equation ${ }^{32,33}$ proposes an empirical model that is based on sorption on heterogeneous surface and has the linear form:

$$
\log \mathrm{qe}=\log \mathrm{K}+1 / \mathrm{n} \log \mathrm{C}_{\mathrm{e}}
$$

Where, $\mathrm{q}_{\mathrm{e}}$ is the amount of adsorbate adsorbed per unit mass of adsorbent $(\mathrm{mg} / \mathrm{g}), \mathrm{C}_{\mathrm{e}}$ is the equilibrium concentration of the adsorbate $(\mathrm{mg} / \mathrm{L})$; ' $\mathrm{K}$ ' and ' $\mathrm{n}$ ' are Freundlich equilibrium coefficient, which are considered to be the relative indicators of adsorption capacity and adsorption intensity.

Table 1: Results of chromium(VI) adsorption isotherm modeling on RPS.

\begin{tabular}{|c|c|c|c|c|c|c|c|}
\hline S.N. & Adsorbent & \multicolumn{2}{|c|}{ Langmuir isotherm } & & \multicolumn{3}{|c|}{ Freundlich isotherm } \\
\hline & & $\mathrm{q}_{\mathrm{m}}(\mathrm{mg} / \mathrm{g})$ & $\mathrm{b}(\mathrm{L} / \mathrm{mg})$ & $\mathrm{R}^{2}$ & $\mathrm{~K}(\mathrm{mg} / \mathrm{g})$ & $1 / \mathrm{n}$ & $\mathrm{R}^{2}$ \\
\hline 1 & RPS & 106.25 & 0.044 & 0.9931 & 6.70 & 0.633 & 0.9678 \\
\hline
\end{tabular}

Langmuir and Freundlich parameters shown in and table 1 were determined from their respective plots. The values of Langmuir equilibrium parameter between 0 and 1 indicated that equilibrium data fits well with Langmuir adsorption isotherm. The values of $1 / \mathrm{n}$ between 0 and 1 indicated that adsorption process was favorable.

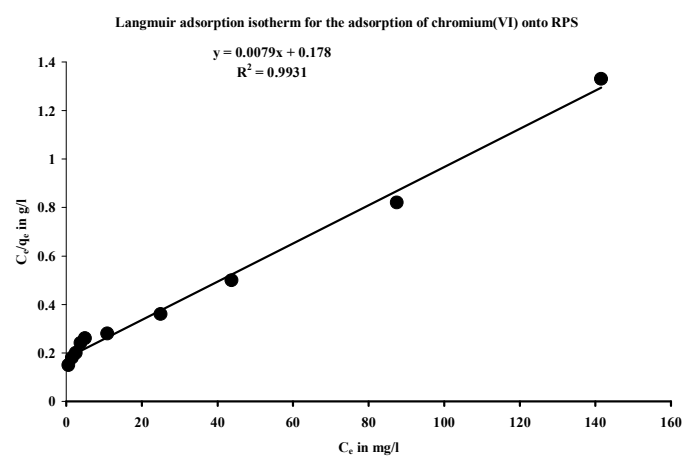

Figure 5: Langmuir Adsorption Isotherm for the adsorption of chromium(VI) onto RPS. 
However, the correlation coefficient values for Langmuir isotherms were found to be greater than that of Freundlich isotherms indicating that the adsorption process is better defined by the Langmuir adsorption isotherm model than by the Freundlich, indicating the homogeneous distribution of active sites on the surface of adsorbents. According to the Langmuir adsorption isotherm as shown in figure 5, the monolayer sorption capacity was found to be $106.25 \mathrm{mg} / \mathrm{g}$.

\section{Kinetic Modeling}

The kinetics for the adsorption of chromium(VI) onto RPS was analyzed using pseudo-first order ${ }^{34,35}$, Pseudo-second order $^{36}$ models. The linear form of the pseudo first order equation of Lagergren model can be expressed as:

$$
\log \left(\mathrm{q}_{\mathrm{e}}-\mathrm{q}_{\mathrm{t}}\right)=\log \mathrm{q}_{\mathrm{e}}-\mathrm{K}_{1} \mathrm{t} / 2.303
$$

Where $\mathrm{q}_{\mathrm{e}}$ and $\mathrm{q}_{\mathrm{t}}$ is the amount of lead(II) ions adsorbed per gram on surface of adsorbent at equilibrium and at time ' $\mathrm{t}$ ' in $\mathrm{mg} / \mathrm{g}, \mathrm{K}_{1}$ is the rate constant of pseudo-first order adsorption $\left(\min ^{-1}\right)$.

The pseudo second order kinetic rate equation can be expressed as:

$$
\mathrm{t} / \mathrm{q}_{\mathrm{t}}=1 / \mathrm{K}_{2} \mathrm{q}_{\mathrm{e}}^{2}+\mathrm{t} / \mathrm{q}_{\mathrm{e}}
$$

Where, $\mathrm{K}_{2}$ is the rate constant for pseudo-second order adsorption in $\left(\mathrm{g} \mathrm{mg}^{-1} \min ^{-1}\right), \mathrm{q}_{\mathrm{e}}$ and $\mathrm{q}_{\mathrm{t}}$ are the amount of lead(II) ions adsorbed (mg/g) at any time ' $t$ ' and at equilibrium time(e) respectively.

Pseudo second order kinetic model for adsorption of chromium(VI) onto RPS

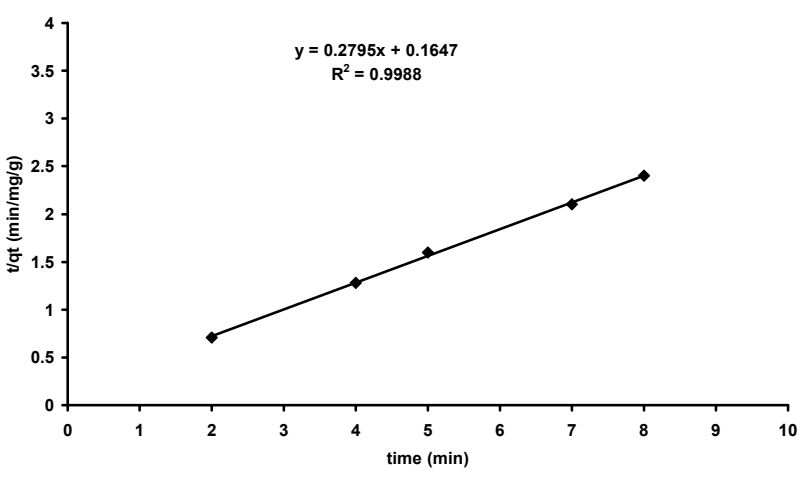

Figure 6: Pseudo second order kinetic model for adsorption of chromium(VI) onto RPS.

The correlation coefficient for pseudo second order was found to be 0.9988 for RPS whereas the correlation coefficient $\left(\mathrm{R}^{2}\right)$ for the pseudo-first order was lower than that of pseudo-second order. This fitness of the experimental data to pseudo second order model as shown in figure 6 ( plot of $t / q_{t}$ versus' $t$ ' ) implies that the rate - limiting step for the adsorption of chromium(VI) onto RPS may be chemisorptions involving valence forces through sharing or exchange of electrons between adsorbent and chromium(VI) ions. ${ }^{36,37}$ 


\section{J. Nepal Chem. Soc., Vol. 39, 2018}

\section{Conclusions}

Removal of chromium(VI) by using agro biomass raw papaya seed powder (RPS) was investigated. Basic adsorption experiments indicated that the adsorption of chromium(VI) onto RPS was an adsorbate, adsorbent dependent process and the optimum adsorption capacity for RPS was achieved at $\mathrm{pH} 1$, with equilibrium contact time of $10 \mathrm{~min}$, initial concentration of $5 \mathrm{mg} / \mathrm{L}$ and adsorption dose of $100 \mathrm{mg}$. The maximum adsorption capacity was found to be $106.25 \mathrm{mg} / \mathrm{g}$ for RPS and results revealed that Langmuir adsorption isotherm model was found to be more applicable than Freundlich adsorption isotherm model for the better description of the adsorption behavior of chromium(VI) ion onto raw papaya seed powder, indicating surface homogeneity. The kinetic data were best fitted by the pseudo-second order kinetic model, which indicated that chemisorptions were the rate - limiting step in the adsorption process. Hence it can be concluded that raw papaya seed powder possesses significant potentiality towards the adsorptive removal of chromium(VI) from aqueous solution.

\section{Acknowledgements}

We wish to thank Head of the Department, Central Department of Chemistry, Tribhuvan University, Kathmandu, Nepal for providing necessary laboratory facility.

\section{References}

1. D. Donmez, and Z. Aksu, Process Biochemistry, 2002, 38, 751.

2. M. Dakiky, A. Khami, A. Manassra, M. Mer'eb, Advances in Environmental Research, 2002, 6, 533.

3. D. C. Sharma, and C.F. Forster, Bioresour. Technol., 1995, 52, 261.

4. H. Li, Z. Li, T. Liu, X. Xiao, Z. Peng, L. Deng, Bioresour. Technol., 2008, 99, 6271.

5. A. K Bhattacharya, S.N. Mandal, S.K. Das, Indian Journal of Chemical Technology, 2006, 13, 576 .

6. S. D. Kim, K. S. Park, M. B. Gu, Journal of Hazardous Materials, 2002, 93, 155.

7. S. Rengaraj, C.K. Joo, Y. Kim, J. Yi, Journal of Hazardous Materials, 2003, 102, 257.

8. G. Vazquez, S. Gonzalez-Alvarez, M. Freire, G. Lopez-Lorenzo, G. Antorrena, Bioresour. Technol., 2001, 82, 247.

9. T. Viraraghavan, R. Saskatchewan, M.M. Dronamrajum, T., J. Environ Sci. Health, 1993, A28, 1261.

10. D. Sud, S. Mahajan, M.P. Kaur, Bioresour. Technol., 2008, 99, 6017.

11. S. E. Bailey, T. J. Olin, R. M. Bricka, D. D. Adrian, Water Res., 1999, 33, 2469.

12. F. N. Acar, Z. Eren, Journal of Hazardous Materials, 2006, B137, 909.

13. S. H. Hasan, K.K. Singh, O. Prakash, M. Talat, Journal of Hazardous Materials, 2008, 152, 356.

14. A. K. Bhattacharya, T.K. Naiya, S.N. Mandal, S.K. Das, Chemical Engineering Journal, 2008, 137, 529.

15. M. Bansal, D. Singh, V.K. Garg, Journal of Hazardous materials, 2009, 171, 83. 
16. D. D. Das, R. Mahapatra, J. Pradhan, S.N. Das, R.S. Thakur, Journal of Colloids and Interface Science, 2000, 232, 235.

17. V. K. Gupta, A. K. Shrivastava, N. Jain, Water Research, 2001, 35, 4079.

18. A. Verma, S. Chakraborty, J.K. Basu, Sep. Purif. Technol., 2006, 50, 336.

19. R. Chand, K. Narimura, H. Kawakita, K. Ohto, T. Watari, K. Inoue, Journal of Hazardous materials, 2009, 163, 245.

20. C. K. Lee, K. S. Low, K. L. Kek, Bioresour. Technol., 1995, 54, 183.

21. S. Bosinco, J. Roussy, E. Guibal, P. Le Cloirec, Environ. Technol., 1996, 17, 55.

22. W. T. Tan, S. T. Ooi, C.K. Lee, Environ. Technol., 1993, 14, 277.

23. M. Jain, V.K. Garg, K. Kadirvelu, Journal of Hazardous Materials, 2010, 171, 328.

24. C.C. Timbo, M. Kandawa-Schulz, M. Amuanyena, H.M. Kawaambwa, Journal of Encapsulation and Adsorption Sciences, 2017, 7, 108.

25. D. Song, K. Pan, A. Tariq, A. Azizuiiah, F. Sun, Z, Li, Q. Xiong, PLoS ONE, 2016, 11, e0167037.

26. H. Gao, Y. Liu, G. Zeng, W. Xu, T. Li, W. Xia, Journal of Hazardous Materials, 2008, 150, 446.

27. E.L. Unuabonah, G.U. Adie, O.O. Lora, G.A. Olalere, Chemical Engineering Journal, 2009, $155,557$.

28. APHA, Standard Methods for the Examination of Waste and Wastewater, $16^{\text {th }}$ ed., 1985, American Public Health Association, Washington, DC.

29. V.K. Gupta, A. Rastogi, A. Nayak, Journal of colloid and Interface science, 2010, 342, 135.

30. P. Bhattarai, K.P. Bohara, M.R. Pokhrel, Journal of Institute of Science and Technology, 2014, 19, 150.

31. A.G. EI-Said, N.A. Badawy, S.E. Garamon, Journal of American Science, 2010, 6, 400.

32. K.N. Ghimire, K. Inoue, K. Ohto, T. Hayashida, Bioresour. Technol., 2008, 99, 32.

33. Y. Bulut, Z. Baysal, J. Environ. Manage., 2006, 78, 107.

34. Y.S. Ho, Scientometrics, 2004, 59, 171.

35. Y.S. Ho, G. McKay, Water Res., 2000, 34, 735.

36. Y.S. Ho, G. McKay, Process Biochem., 1999, 34, 451.

37. D. Liao, W. Zheng, X. Li, Q. Yang, X. Yue, L. Guo, G. Zeng, Journal of Hazardous Materials, 2010, 177, 126. 